Note

\section{Structural Analysis of $\beta$-Glucans from a Killer Toxin Sensitive Yeast, Saccharomyces cerevisiae, and a Killer-Resistant Mutant}

\author{
Tasuku NakajIma, Keishi Aoyama, \\ Eiji IChishima and Kazuo Matsuda* \\ Department of Agricultural Chemistry, \\ Faculty of Agriculture, Tohoku University, \\ Tsutsumidori-Amarniyamachi, Sendai 980, Japan
}

Received December 15, 1988

Killer yeast strains secrete protein toxins which kill sensitive strains., ${ }^{1,2)}$ The killer toxin ( $\mathrm{K}_{1}$ type) of Saccharomyces cerevisiae is coded by a double-stranded RNA plasmid ${ }^{3)}$ and inhibits the pumping of protons in sensitive cells. ${ }^{4 /}$ Recently, Hutchins and Bussey showed that yeast cell wall $(1 \rightarrow 6)-\beta$-D-glucan exhibits receptor activity toward the killer toxin. ${ }^{5}$ They reported that the killer toxin bound to a $(1 \rightarrow 6)-\beta$-D-glucan-(pustulan)Sepharose column and that the receptor activity was lost on treatment of cell walls with periodate or $(1 \rightarrow 6)-\beta$-Dglucanase, on the other hand, the receptor activity remained after treatment with $\alpha$-amylase or $(1 \rightarrow 3)-\beta$-Dglucanase.

In this study, to characterize the structure of the $\beta$ glucan acting as a component of the killer receptor, we compared the chemical structures of cell wall $\beta$-glucans prepared from Saccharomyces cerevisiae S-14a, a killer toxin-sensitive strain, and $S$. cerevisiae S-14-96, a killer- resistant mutant, both of which were kindly donated by Dr. H. Bussey, McGill University, Montreal, Canada.

The killer toxin-sensitive strain and the resistant mutant were grown at $30^{\circ} \mathrm{C}$ with shaking in YPD medium containing $1 \%$ yeast extract, $2 \%$ peptone and $2 \%$ glucose. The cells were harvested at the late-log phase, washed with distilled water and then lyophilized. $\beta$-Glucans were prepared by a modification of the method of Manners et al ${ }^{6)}$ (Fig. 1). The yield and carbohydrate content of each fraction did not significantly differ between the killersensitive and killer-resistant cells (Table I). The $\beta$-D-glucan fractions (Fraction $C$ ) from both types of yeast cells were

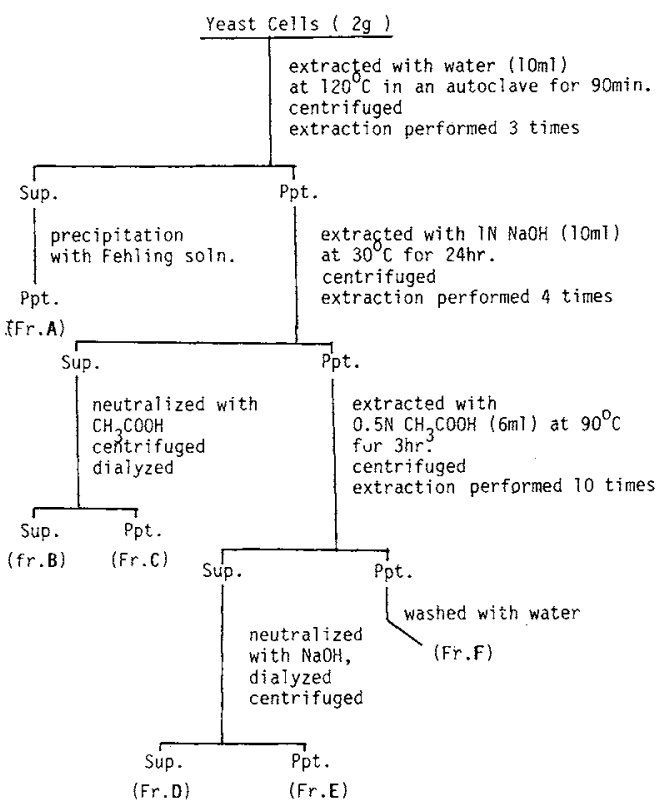

Fig. 1. Scheme for the Sequential Extraction of Polysaccharides from Yeast Cells.

Table I. Yields and Carbohydrate Contents of the Fractions

\begin{tabular}{lccccc}
\hline Yeast strain & Fr. A & Fr. B & Fr. C & Fr. D & Fr. F \\
\hline S-14a & $4.0^{a}(3.9)^{b}$ & $32.2(7.5)$ & $7.9(3.8)$ & $5.1(2.0)$ & $11.0(6.1)$ \\
(Sensitive) & $\mathrm{M} / \mathrm{G}=100 / 0^{c}$ & $\mathrm{M} / \mathrm{G}=55 / 45$ & $\mathrm{M} / \mathrm{G}=4 / 96$ & $\mathrm{M} / \mathrm{G}=16 / 84$ & $\mathrm{M} / \mathrm{G}=0 / 100$ \\
S-14-96 & $3.9(3.7)$ & $33.1(8.0)$ & $10.2(4.7)$ & $5.8(1.8)$ & $11.8(6.7)$ \\
(Resistant) & $\mathrm{M} / \mathrm{G}=100 / 0$ & $\mathrm{M} / \mathrm{G}=78 / 22$ & $\mathrm{M} / \mathrm{G}=5 / 95$ & $\mathrm{M} / \mathrm{G}=11 / 89$ & $\mathrm{M} / \mathrm{G}=0 / 100$
\end{tabular}

a Weight $\%$ as to the dry cell weight.

${ }^{b}$ Carbohydrate contents were determined by the method of Dubois et al ${ }^{11)}$ and expressed as weight $\%$ as to the dry cell weight.

c The carbohydrate compositions of the fractions are expressed as the mannose to glucose ratio. M, D-mannose; $\mathrm{G}, \mathrm{D}$-glucose; - , negligible.

¿ Fraction $\mathrm{E}$ was neglected because of its negligible yield.

* Professor emeritus. Present address: Iwaki-Meisei University, Faculty of Science and Technology, Iwaki-shi, Fukushima 970, Japan. 
Table II. Methylation Analysis of Native and Degraded $\beta$-Glucan Fractions

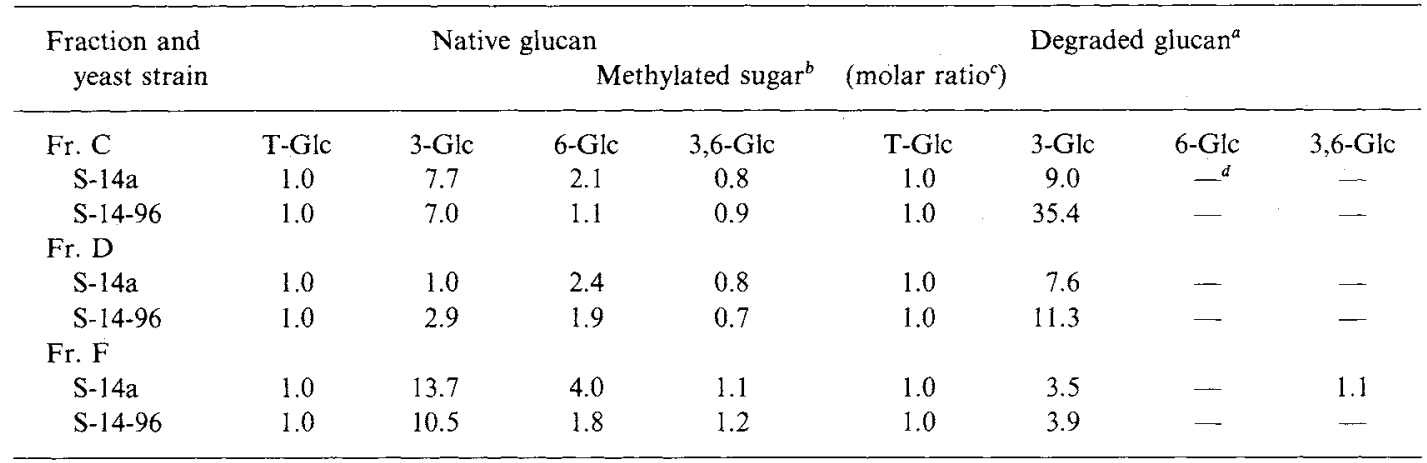

a Residual glucan after controlled Smith degradation.

$b$ Partially methylated alditol acetate derivatives, T-Glc (1,5-di- $O$-acetyl-2,3,4,6-tetra-O-methyl-glucitol), 3-Glc (1,3,5-tri- $O$-acetyl-2,4,6-tri- $O$-methyl-glucitol), 6-Glc (1,5,6-tri- $O$-acetyl-2,3,4-tri- $O$-methyl-glucitol) and 3,6Glc (1,3,5,6-tetra- $O$-acetyl-2,4-di- $O$-methyl-glucitol).

c Relative to T-Gic.

¿ Not detected.

further purified by gel filtration on a Sepharose CL-6B column. Through this step, a major polysaccharide fraction was separated from contaminating proteins. ${ }^{7}$ Other $\beta$-glucan fractions (D and $F$ ) were not soluble in alkali, so they were treated with $\alpha$-amylase and protease to remove contaminating glycogen and proteins. ${ }^{7)}$ The purified $\beta$-glucan fractions ( $C, D$ and $F$ ) were subjected to structural analyses.

Each sample was divided into two portions. One was directly methylated, and the other was first subjected to controlled Smith degradation ${ }^{8)}$ and then methylated. The methylation and acid hydrolysis of the methylated samples were performed according to the methods of Hakomori ${ }^{9}$ ) and Lindberg, ${ }^{10}$ respectively. Analysis of the partially methylated alditol acetates was performed by GLC-mass spectrometry, with a JEOL-OIG-2 gas chromatographmass spectrometer, on a glass column of $3 \% \mathrm{OV}-210$ on Supercoport at $180^{\circ} \mathrm{C}$. Table II compares the data obtained on methylation analysis of $\beta$-glucans for the killersensitive and killer resistant strains. In the alkali-soluble $\beta$ glucan fraction ( $\mathrm{Fr} . \mathrm{C}$ ), no significant difference between the killer-sensitive and resistant cells was observed. On the other hand, their alkali insoluble $\beta$-glucan fractions ( $D$ and $F$ ) differed in the ratio of 1,6-linked glucose to 1,3linked glucose residues (2,3,4-tri- $O$-methyl glucose/2,4,6tri- $O$-methyl glucose). For both fractions, the killer toxinsensitive cells showed a higher proportion of 1,6-linked glucose residues (Fr. D: sensitive-2.4, resistant-0.7; Fr. F: sensitive-0.3, resistant- 0.2 ).

Smith degradation should cause degradation of 1,6 linked glucose residues and leave 1,3-linked glucosyl backbone structures intact (Table II). The absence of 2,4-di$O$-methyl glucose in the hydrolyzates of the methylated Smith degradation products indicates that a part of the 1,6-linked glucose residues is located in the backbone of the glucans, in other words, the $\beta$-1,3-linked glucose chain is linked through $\beta-1,6$-glucosyl interchain linkages. The results also showed that the killer-sensitive strain had a shorter 1,3-linked glucosyl unit chain structure than the resistant strain, especially in Fractions $C$ and $D$.

The above results support the involvement of a yeast cell wall $(1 \rightarrow 6)-\beta$-D-glucan as a component of the receptor for the killer toxin, as previously reported. ${ }^{5)}$ The report also showed that the receptor activity remained in the alkali and acid insoluble cell wall fraction. This agree with our data showing the higher proportion of $\beta-1,6$-linked glucose residues in the alkali-insoluble $\beta$-glucan fraction from the killer-sensitive strain. However, the results of structural analysis indicates that the possibility of the presence of a linear $(1 \rightarrow 6)-\beta$-D-glucan in the cell wall is small. The receptor glucan may be a highly branched $\beta-1,3$ and $\beta-1,6$-glucan with a laminated structure, and probably the linear parts of $\beta-1,6$-linked glucose units are located in the side chains or inner part of the $\beta$-1,6-linked backbone.

Acknowledgment. The authors wish to thank Dr. $\mathrm{H}$. Bussey, Department of Biology, McGill University, for supplying the killer-sensitive and killer-resistant Saccharomyces cerevisiae strains.

\section{References}

1) R. G. E. Palfree and H. Bussey, Eur. J. Biochem., 93, 487 (1979).

2) D. J. Tipper and K. A. Bastian, Microbiol. Rev., 48, 125 (1984).

3) R. B. Wickner, Bacteriol. Rev., 40, 757 (1976).

4) P. de la Pena, F. Barros, S. Gascon, P. S. Lazo and S. Ramos, I. Biol. Chem., 256, 10420 (1981). 
5) K. Hutchins and H. Bussey, J. Bacteriol., 154, 161 (1983).

6) D. J. Manners, A. J. Masson and J. C. Patterson, Biochem. J., 135, 19 (1973).

7) T. Nakajima, H. Nishihara, Y. Chiba and K. Matsuda, J. Ferment. Technol., 66, 251 (1988).

8) I. J. Goldstein, G. W. Hey, B. A. Lewis and F. Smith, in "Methods in Carbohydrate Chemistry," Vol. 5, ed. by R. L. Whistler et al., Academic Press, New York, 1972, pp. $361 \sim 370$.

9) S. Hakomori, J. Biochem., 55, 205 (1964).

10) B. Lindberg, in "Methods in Enzymology," Vol. 28, ed. by V. Ginsberg, Academic Press, New York, 1972, pp. 178 195 .

11) M. Dubois, K. A. Gilles, J. K. Hamilton, P. A. Rebers and F. Smith, Anal. Chem., 28, 350 (1956). 